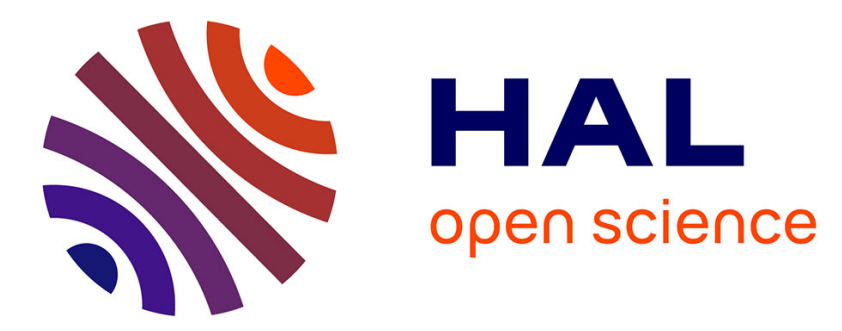

\title{
Conceptual development and critical attitude in physics education: A pathway in the search for coherence Laurence Viennot
}

\section{To cite this version:}

Laurence Viennot. Conceptual development and critical attitude in physics education: A pathway in the search for coherence. Pietrocola Pinto de Oliveira. Viennot, L. 2019, Conceptual development and critical attitude in physics education: Upgrading Physics Education to Meet the Needs of Society, Springer International Publishing, pp.189-198, 2019. hal-01739195

\section{HAL Id: hal-01739195 \\ https://hal.science/hal-01739195}

Submitted on 20 Mar 2018

HAL is a multi-disciplinary open access archive for the deposit and dissemination of scientific research documents, whether they are published or not. The documents may come from teaching and research institutions in France or abroad, or from public or private research centers.
L'archive ouverte pluridisciplinaire HAL, est destinée au dépôt et à la diffusion de documents scientifiques de niveau recherche, publiés ou non, émanant des établissements d'enseignement et de recherche français ou étrangers, des laboratoires publics ou privés. 
Conceptual development and critical attitude in physics education:

\author{
A pathway in the search for coherence \\ Laurence Viennot \\ LDAR, Laboratoire André Revuz, EA 4434
}

\begin{abstract}
Viennot, L. 2018. Conceptual development and critical attitude in physics education: A pathway in the search for coherence, In M. Pietrocola and C. Haagen-Schützenhöfer (eds): Perspectives in physics teaching and learning to face challenges in present society, Dordrecht: Springer.
\end{abstract}

\title{
Introduction
}

From the outset of physics education research in the 1970s, an implicit or explicit target was to facilitate better comprehension of accepted physics in students at all academic levels. But a consensus has long since been reached that what we call "accepted physics" had to be re-thought for teaching, and Kattmann and Duit (1998) proposed the term "educational reconstruction" to designate this process. From this perspective, the very basis of reflection about the design of a learning environment for a given audience combines examination of the content and of students' "prescientific conceptions". Of course, decisions about the design and implementation of learning environments are also influenced by the international context, with current consensus around a series of teaching goals: to engage students with physics, (and therefore) to simplify the contents to be taught in helping students to construct a preliminary sense of the nature of science, stressing the role of reasoning and reasoned inquiry and developing many other abilities-most prominently, critical stance. A stress on competencies can be observed in many official texts; for instance, the European Commission foregrounds the need "to develop the competencies for problem-solving and innovation, as well as analytical and critical thinking that are necessary to empower citizens to lead 
personally fulfilling, socially responsible and professionally-engaged lives" (European Commission 2015). Given this emphasis on competencies in combination with the desire to simplify physics, there is a risk that conceptual structuring may be disregarded, potentially resulting in serious inconsistencies in pedagogical resources. This in turn demands increased critical vigilance among students and teachers, inviting the research question What links can be identified between the development of conceptual understanding and critical attitude in physics students - or, in operational terms: Can we help students to develop their critical thinking without a conceptual basis?

\section{Analysing the interplay between conceptual understanding and critical attitude: What are we talking about?}

These questions identify a need to further specify two aspects of a student's intellectual trajectory-conceptual understanding and critical attitude-which are the focus of this chapter. As noted above, a process of educational reconstruction is needed to define what we mean by "conceptual understanding" of the content in play. The proposed framework (Viennot 2015a, 2016b; see Figure 1) emphasises the importance of two factors. First, conceptual coherence is seen as pivotal in the process of educational reconstruction, echoing a vision of science as pursuing a coherent, predictive and parsimonious description of the material world (Jenkins 2007; Ogborn 1997). This search for coherence is explored in the content analysis, as well as in what we describe as students' ideas. Secondly, beyond students' existing ideas and ways of reasoning, it is proposed to take account of teaching rituals. As some of these rituals are found to be in a kind of resonance with students' ideas, the label "echo-explanation" is used to designate such cases-for instance, using "ray boxes" without any caveat (Viennot 2006). In any event, the persistence of these rituals over time (Viennot 2016) suggests that they are linked to factors that may influence the decisions of course designers and teachers. For that reason, these rituals and their likely determinants should be considered in any definition of a conceptual teaching target.

On this view, the global coherence of a given conceptual target entails a particular "spotlighting" of the relevant content (Viennot 2003, 2015a). This means that explicit decisions must be made about centrally important concepts and-most importantly—about the links to be highlighted. The whole process should respect the epistemic need for parsimony and the constraint of accessibility. The type of critical attitude considered here 
involves localizing an explanation's possible incoherence or detecting its possible incompleteness. Socio-scientific forms of critique such as the ability to evaluate texts and their sources in terms of possible asymmetries of power or the status of experts (Jimenez \& Puig 2012) are not examined here.

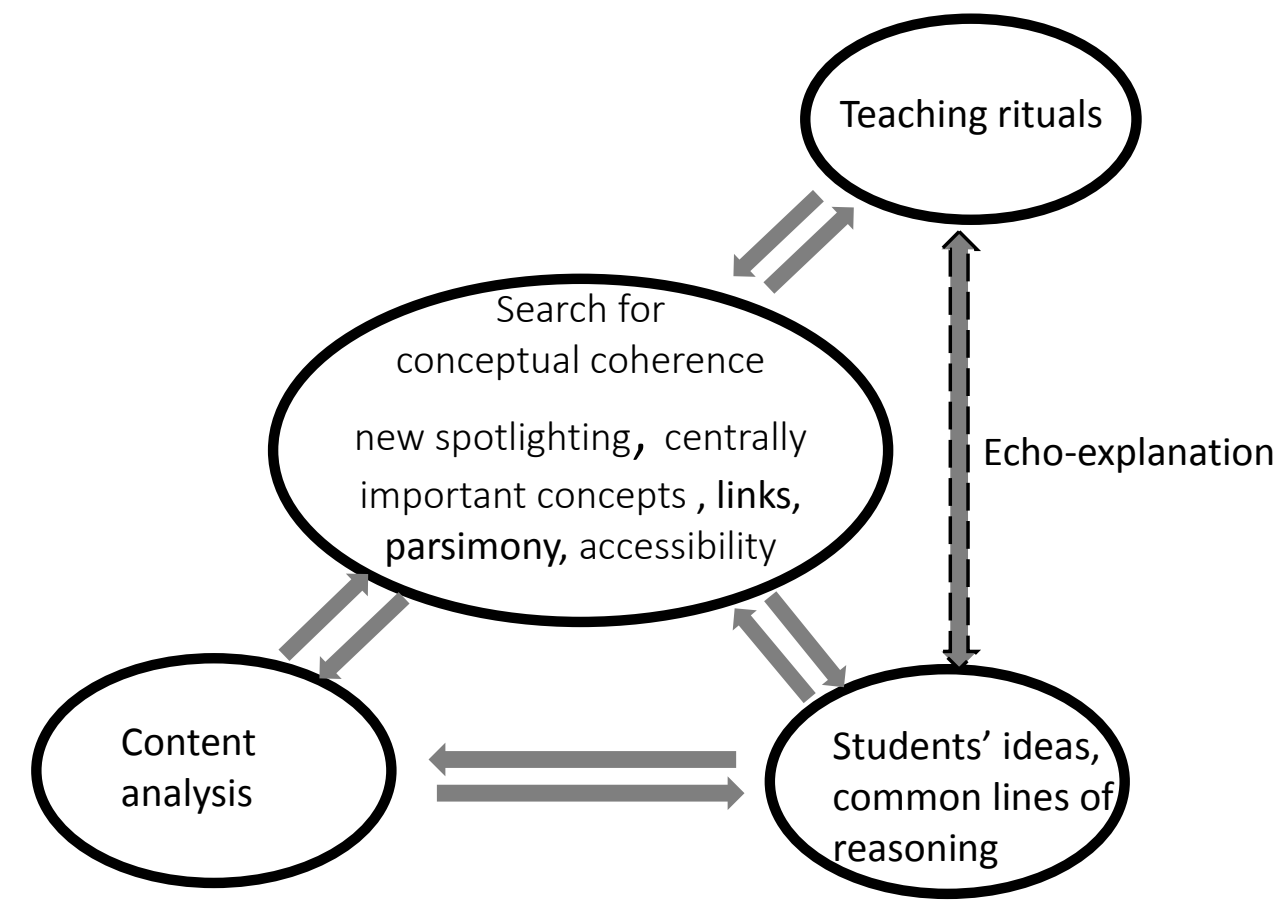

Figure $1 \mathrm{~A}$ framework to define the conceptual content to be taught (Viennot 2015a, 2015b)

That said, an investigation of how students express or fail to express possible criticisms of an explanation does not exclude other psycho-cognitive factors. Clearly, posing a critical question requires some awareness of one's own state of comprehension and of what it is to learn science. Such questioning also evidences a search for intellectual satisfaction (often manifesting as frustration) (Viennot 2006; Mathé \& Viennot 2009) and depends in part on such factors as self-esteem or self-efficacy (Bandura 2001). As these metacognitive and affective components of students' critical attitude seem a priori difficult to disentangle, they are designated here by the compound label 'metacognitive-critical-affective' (MCA).

The investigations reported below examined how these MCA factors may evolve in conjunction with conceptual comprehension, focusing on students' intellectual dynamics of co-development during an interaction targeting conceptual progress. These studies entailed fine grain analyses of changes in students' intellectual pathways over time.

\section{A few investigations}


Each of the reported studies centred on a particular physics topic, and several involved extended individual interviews (Mathé \& Viennot 2009; Décamp \& Viennot 2015; Viennot \& Décamp 2016a, 2016b). In each case, conditions were designed for a concept-driveninteractive pathway (CDIP) (see Viennot \& de Hosson 2015). A CDIP is a series of eventsinputs from the interviewer and responses from the student, possibly involving experiments, questions or requests and discussion — informed by a search for coherence and intellectual satisfaction. In line with the teaching experiment method (Komorek \& Duit 2004), the interaction is structured and guided to allow students to express their initial thoughts and reactions to various events. A CDIP is also progressive, in that what is understood at a given step may serve to construct the next stage of knowledge, offering opportunities for students to critique a few explanations. The three studies summarised here delineate a preliminary but consistent landscape constituted by the key intellectual dynamics of students' codevelopment.

\section{Radio carbon dating}

Although not the first in the series, a study centred on the topic of radiocarbon dating (Viennot 2014a, Décamp \& Viennot 2015) provides a good illustration of our initial results. Beyond the well-known exponential decay of radiocarbon in dead organisms and the role of

${ }^{14} \mathrm{C}$ half-life (5730 years), a relatively complete and coherent explanation of this process should include at least the following conceptual nodes:

1 the need to know the initial proportion of radiocarbon to ordinary carbon in an organism at the time of its death;

2 the uniformity of this quantity in the atmosphere and living beings;

3 the constancy in time of this quantity;

4 the process of formation of radiocarbon;

5 the process of radioactive decay of radiocarbon;

6 how the balance between the corresponding numbers per second of radiocarbon atoms involved in these two processes results in a steady value of $\left[{ }^{14} \mathrm{C} /{ }^{12} \mathrm{C}\right]$ in the atmosphere;

7 the constancy of the total number of nuclei (radio carbon + nitrogen);

8 the multiplicative effect of the existing numbers of radiocarbon and nitrogen nuclei in the destruction and creation of ${ }^{14} \mathrm{C}$ nuclei, respectively;

9 how this multiplicative structure explains the stable proportion of radiocarbon to ordinary carbon in the atmosphere. 
We selected five online documents providing explanations that were incomplete with regard to the above list. Using conceptual nodes 7,8 and 9, we also designed a sixth document to explain how a steady state ${ }^{14} \mathrm{C}$ population can be reached and maintained from an unbalanced initial situation. Ten prospective teachers were then presented with these documents in order of increasing completeness. For each document, students were asked to indicate their level of satisfaction with the explanation provided and whether they would need further information. Questions that might have been posed in response to the first and least complete explanations would include "How is it that there is a constant proportion of radiocarbon in the atmosphere? There is no radiocarbon decay in the atmosphere?"

Transcripts were processed at two levels of analysis: a conceptual level (which is not commented on here) and MCA aspects. Our MCA indicators included levels of agreement, types of questions posed-specifically, anecdotal or 'crucial' (that is, concerning the above conceptual nodes) - and levels of intellectual satisfaction or frustration. The findings indicated that most students needed to reach a threshold of comprehension beyond mere logical necessity before activating their critical potential. Once this (student-dependent) threshold was reached, agreement, moderate satisfaction and anecdotal questions disappeared, to be replaced by frustration, crucial questions, critiques (including self-critiques) and an active search for comprehension until, finally, the student was satisfied with the last explanation. We designated this intellectual dynamic as delayed critique. We also observed that two students who knew the topic very well were satisfied both with their own responses and with all the presented explanations (however incomplete). We described this form of critical passivity as expert anaesthesia.

\section{Hot air balloon}

The above findings align with previous results related to the topic of hot air balloons (Mathé \& Viennot 2009). One typical teaching ritual presents hot air balloons as isobaric when calculating the internal temperature needed for take-off (see for instance Giancoli 2005). Quasi-unanimously, teachers offer no objection to this hypothesis ( $N=129 / 130$, Viennot 2014c), even though their knowledge of this domain should tell them otherwise. Specifically, they should know that an isobaric situation inevitably results in a crash, as all kinds of flotation link to a gradient of pressure, or that the same pressure on both sides of an envelope cannot result in a force exerted on this envelope. 
For the purposes of this study, 14 prospective journalists (in their third year at university) were asked for their opinions of an article explaining how a hot air balloon works. This mentioned the inconsistent hypothesis referred to above, and while interviewees realized at various moments that the hypothesis was absurd, there was in most cases a noticeable delay in explicitly criticising the article itself. This result can now be understood as a case of delayed critique.

\section{Survival blanket}

A subsequent investigation revealed another intellectual dynamic of interest. A small group $(\mathrm{N}=7)$ of prospective teachers (in their fourth year at university) were interviewed about how to use a survival blanket for protection against the cold (Viennot \& Décamp 2016a). Here again, a delayed critique dynamic was observed. In this case, students' judgments were strongly influenced by a preconception: that the best possible way to protect against cold with a survival blanket was to ensure the maximum reflection of 'heat' towards the body. Not surprisingly, then, participants were found to have difficulty in critiquing texts that presented the same view. In the case of one participant, however, an element of information available from the start (that the gold side is more emissive than the silver side) was used to trigger an 'early critique', so confirming that this dynamic was logically possible, although the other participants seemed unable to access it.

\section{Recapitulation and discussion}

The three experiments described above supported a first recapitulation of our findings.

\begin{tabular}{|c|c|c|c|c|}
\hline $\begin{array}{l}\text { Topic } \\
\text { Authors }\end{array}$ & Sample & $\begin{array}{l}\text { Delayed } \\
\text { critique }\end{array}$ & $\begin{array}{c}\text { Early } \\
\text { critique }\end{array}$ & $\begin{array}{c}\text { Expert } \\
\text { anaesthesia }\end{array}$ \\
\hline $\begin{array}{l}\text { Isobaric' hot air balloon } \\
\text { (Mathé \& Viennot, 2009) }\end{array}$ & $\begin{array}{l}14 \\
\text { Future science journalists }\end{array}$ & 12 & 2 & 0 \\
\hline $\begin{array}{l}\text { Radiocarbon dating: Constancy of } \\
{ }^{14} \mathrm{C} /{ }^{12} \mathrm{C} \text { ratio in the atmosphere } \\
\text { (Décamp \& Viennot, 2015) }\end{array}$ & $\begin{array}{c}10 \\
\text { Student teachers } \\
\text { (physics) }\end{array}$ & 8 & 0 & 2 \\
\hline $\begin{array}{l}\text { Survival blanket: 'Put the silver } \\
\text { side inside to protect against cold' } \\
\text { (Viennot \& Décamp, 2016a) }\end{array}$ & $\begin{array}{c}7 \\
\text { Student teachers } \\
\text { (physics) }\end{array}$ & 6 & 1 & 0 \\
\hline
\end{tabular}


Table 1. Numbers of interviewees manifesting each of the three identified intellectual dynamics in the three investigations summed up above. The diagrams in col. 3 to 5 symbolize the respective evolution of conceptual understanding (above) and critical attitudes (below) in students during the interview.

These results - recently completed by a study on the topic of osmosis (Viennot \& Décamp 2016b) — support Willingham's view that "Critical thinking is not a set of skills that can be deployed at any time, in any context" (Willingham 2007). To put it another way, students' critical development cannot be seen as independent of their conceptual progress. While advanced students' responses to incomplete or incoherent explanations show that they are searching for coherence, most of them need to reach a threshold of comprehension beyond logical necessity before expressing their intellectual frustration-a symptom of delayed critique. In rare cases, this dynamic is observed after a very short delay (early critique). We have also observed that some students or teachers exhibit strong critical passivity towards certain defective explanations, even when they understand the topic very well; we call this (absent) intellectual dynamic expert anaesthesia. This syndrome is a good candidate to explain (at least in part) the remarkable stability of some teaching rituals (Viennot \& Décamp 2016b), which can scarcely be ascribed only to habit.

It is striking that the above studies illuminate two distinct intellectual dynamicsdelayed critique and expert anaesthesia - that are both marked by strong or total critical passivity. In the interpretations that (hypothetically) present themselves, conceptual development seems to play two opposing roles. In the case of delayed critique, conceptual comprehension is defective, and the respondent's energy seems mobilised by a search for previous knowledge and a desire to understand the topic before offering any critical judgment. In the second case, experts' sense of competence seems to block any concerns about the presented explanation, and it seems possible that they may unconsciously complete what is missing in the given text or drawing. Two circumstances are likely to aggravate this situation: when a common idea or echo-explanation affects experts' judgment, or when a faulty explanation leads to a correct answer (see for instance Kahneman 2009, p. 52).

In any case, these findings serve to clarify the role of metacognive-critical-affective factors in students' intellectual dynamics. Metacognition and psycho-affective factors have long been thought to correlate with student cognitive performance (e.g. Pintrich et al. 1993; 
Rhöneck et al. 1998; Launkenmann et al. 2003). Here, it is important to note the focus on intellectual processes rather than on correlations; for instance, the two opposing roles of conceptual expertise in our findings would, if further confirmed, invalidate any conclusion that relied on mere correlation with a given psycho-cognitive factor. Fine-grained analyses of the kind described here seem essential in meeting the clearly urgent need to incorporate critical development in the design of teacher formation.

\section{References}

Bandura, A. (2001). Social cognitive theory: An agentic perspective. Annual review of psychology, $52(1), 1-26$.

Décamp, N. \& Viennot, L. (2015). Co-development of conceptual understanding and critical attitude: analysing texts on radiocarbon dating. International Journal of Science Education, 37 2038-63.

European Commission, 2015. Science education for responsible citizenship, Report EUR 26893 EN, Brussels

Giancoli, D.C. (2005). Physics (6th ed): Instructor Resource Center CD-ROM, Prentice Hall. Jenkins, E. W. (2007). School science: A questionable construct? Journal of Curriculum Studies, 39, 265-282. doi:10.1080/00220270701245295.

Jimenez- Aleixandre, M. P., \& Puig, B. (2012). Argumentation, evidence evaluation and critical thinking. In B.J. Fraser, K. Tobin, \& C. McRobbie (Eds.), Second international handbook of science education (pp. 1001-1015). Dordrecht: Springer.

Kahneman, D. (2012) Thinking Fast and Slow. London Penguin books.

Kattmann U. \& Duit R. (1998): The model of educational reconstruction. Bringing together issues of scientific clarification and students' conceptions. In Bayrhuber B(ed): What-Why-How? Research in Didaktik of biology, 253-262.

Komorek, M. \& Duit, R. (2004). The teaching experiment as a powerful method to develop and evaluate teaching and learning sequences in the domain of non-linear systems. International Journal of Science Education, 26(5), 619-633.

Laukenmann, M., Bleicher, M., Fuller, S., Gläser-Zikuda, M., Mayring, P., \& Rhöneck, C. V. (2003). An investigation of the influence of emotional factors on learning in physics instruction. International Journal of Science Education, 25(4), 489-507.

Mathé, S., \& Viennot, L. 2009. Stressing the coherence of physics: Students journalists' and science mediators' reactions, Problems of education in the 21 st century. 11 (11), 104-128.

Ogborn, J. (1997). Constructivist metaphors of learning science. Science \& Education, 6, 121-133. doi:10.1023/A:1008642412858

Pintrich, P. R., Marx, R. W., \& Boyle, R. A. (1993). Beyond cold conceptual change: The role of motivational beliefs and classroom contextual factors in the process of conceptual change. Review of Educational Research, 63(2),167-199.

Rhöneck, C. V., Grob, K., Schnaitmann, G. W., \& Völker, B. (1998). Learning in basic electricity: how do motivation, cognitive and classroom climate factors influence achievement in physics?

International Journal of Science Education, 20(5), pp. 551-565.

Viennot, L. 2003. Teaching physics. Dordrecht: Kluwer Ac. Pub.

Viennot L. 2006. Teaching rituals and students' intellectual satisfaction, Phys. Educ. 41, 400-408.

Viennot, L. 2014a. Codevelopment of conceptual understanding and critical attitude: an essential condition for physics learning. Invited address. Frontiers of fundamental physics FFP14, Marseille July 2014. PoS(FFP14)011 http://webcast.in2p3.fr/videos-

ffp14 coevelopment of conceptual understanding and critical attitudean essential condition for $p$ hysics learning laurence viennot

Viennot, L. 2014b. Thinking in physics The pleasure of reasoning and understanding Dordrecht: Springer/Grenoble Sciences. 
Viennot, L. 2015a. Spotlighting a content for teaching: research examples at university level, plenary address, L'esperienza del PLS: guardando oltre --Roma, 11-12 maggio 2015, text on request from the author

Viennot, L. 2015b . Thinking the content for physics education research and practice, in Fazio C. \& Sperandeo-Mineo R.M. (Eds.) Teaching/Learning Physics. Integrating Research into Practice, Proceedings of the GIREP/MPTL 2014 International Conference, Università degli Studi di Palermo, ISBN 978-88-907460-7-9, pp. 61-79 - http://www1.unipa.it/girep2014/proceedings/GIREP-

MPTL\%202014\%20Conference\%20Proceedings.pdf

Viennot, L. 2016. The persistence of Teaching Rituals, Physics Education 51030104

Viennot, L. \& De Hosson, C. 2015. From a Subtractive to Multiplicative Approach, A Concept-driven Interactive Pathway on the Selective Absorption of Light, International Journal of Science Education, 37:1, 1-30. DOI: 10.1080/09500693.2014.950186

Viennot \& Décamp, L. 2016a. Co-development of conceptual understanding and critical attitude: toward a systemic analysis of the survival blanket, European Journal of Physics, 37 doi:10.1088/01430807/37/1/015702

Viennot \& Décamp, L. 2016b . Conceptual and critical development in student teachers: First steps towards an integrated comprehension of osmosis, International Journal of Science Education, http://dx.doi.org/10.1080/09500693.2016.1230793

Willingham, D. T., 2008 Critical thinking: why is it so hard to teach? Arts Educ. Policy Rev. 109, 2132 . 